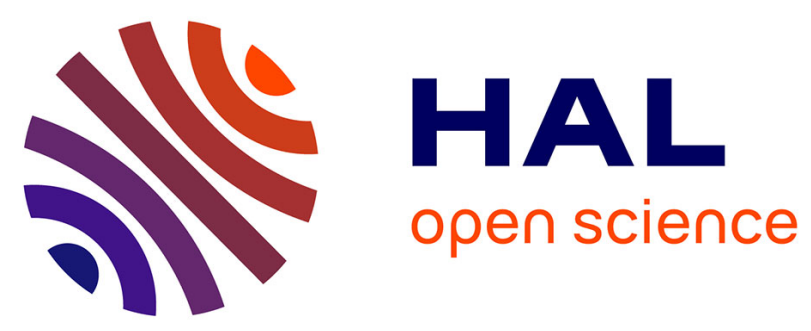

\title{
A round Robin test of the uncertainty on the measurements of the thermoelectric dimensionless figure of merit of Co0.97Ni0.03Sb3
}

Eric Alleno, David Bérardan, Céline Byl, Christophe Candolfi, Ramzy Daou, Rodolphe Decourt, Emmanuel Guilmeau, Sylvie Hébert, Jiří Hejtmánek, Bertrand Lenoir, et al.

\section{To cite this version:}

Eric Alleno, David Bérardan, Céline Byl, Christophe Candolfi, Ramzy Daou, et al.. A round Robin test of the uncertainty on the measurements of the thermoelectric dimensionless figure of merit of Co0.97Ni0.03Sb3. Review of Scientific Instruments, 2015, 86 (1), 011301 (9 p.). 10.1063/1.4905250 . hal-01108894

\section{HAL Id: hal-01108894 \\ https://hal.science/hal-01108894}

Submitted on 31 May 2021

HAL is a multi-disciplinary open access archive for the deposit and dissemination of scientific research documents, whether they are published or not. The documents may come from teaching and research institutions in France or abroad, or from public or private research centers.
L'archive ouverte pluridisciplinaire HAL, est destinée au dépôt et à la diffusion de documents scientifiques de niveau recherche, publiés ou non, émanant des établissements d'enseignement et de recherche français ou étrangers, des laboratoires publics ou privés. 


\title{
Invited Article: A round robin test of the uncertainty on the measurement of the thermoelectric dimensionless figure of merit of $\mathrm{Co}_{0.97} \mathrm{Ni}_{0.03} \mathrm{Sb}_{3}$
}

\author{
E. Alleno, ${ }^{1, a)}$ D. Bérardan, ${ }^{2}$ C. Byl, ${ }^{2}$ C. Candolfi, ${ }^{3}$ R. Daou,${ }^{4}$ R. Decourt, ${ }^{5}$ E. Guilmeau, ${ }^{4}$ \\ S. Hébert, ${ }^{4}$ J. Hejtmanek, ${ }^{6}$ B. Lenoir,${ }^{3}$ P. Masschelein, ${ }^{3}$ V. Ohorodnichuk, ${ }^{3}$ M. Pollet,${ }^{5}$ \\ S. Populoh, ${ }^{7}$ D. Ravot, ${ }^{8}$ O. Rouleau, ${ }^{1}$ and M. Soulier ${ }^{9}$ \\ ${ }^{1}$ Institut de Chimie et Matériaux Paris-Est, UMR CNRS-UPEC 7182, 2-8, rue Henri Dunant, \\ 94320 Thiais, France \\ ${ }^{2}$ SP2M, ICMMO (CNRS UMR 8182), Université Paris-Sud, 91405 Orsay, France \\ ${ }^{3}$ Institut Jean Lamour, UMR 7198 CNRS-Université de Lorraine, Parc de Saurupt, 54042 Nancy Cedex, France \\ ${ }^{4}$ Laboratoire CRISMAT, UMR6508 CNRS_ENSICAEN, 6 Bd du Maréchal Juin, 14050 Caen Cedex, France \\ ${ }^{5}$ ICMCB, CNRS and Université de Bordeaux, UPR 9048, 33600 Pessac, France \\ ${ }^{6}$ Institute of Physics of ASCR, v.v.i, Na Slovance 2, 18221 Praha 8, Czech Republic \\ ${ }^{7}$ Empa-Swiss Federal Laboratories for Materials Science and Technology, Materials for Energy Conversion, \\ Überlandstrasse 129, CH-8600 Dübendorf, Switzerland \\ ${ }^{8}$ Institut Charles Gerhardt, UMR 5253, CNRS_Université Montpellier 2, Place Eugène Bataillon, \\ 34095 Montpellier cedex 5, France \\ ${ }^{9}$ Laboratoire de Thermoélectricité, CEA Grenoble, 17 rue des Martyrs, 38054 Grenoble, France
}

(Received 5 May 2014; accepted 19 November 2014; published online 8 January 2015)

\begin{abstract}
A round robin test aiming at measuring the high-temperature thermoelectric properties was carried out by a group of European (mainly French) laboratories (labs). Polycrystalline skutterudite $\mathrm{Co}_{0.97} \mathrm{Ni}_{0.03} \mathrm{Sb}_{3}$ was characterized by Seebeck coefficient ( 8 labs), electrical resistivity ( 9 labs), thermal diffusivity (6 labs), mass volume density (6 labs), and specific heat (6 labs) measurements. These data were statistically processed to determine the uncertainty on all these measured quantities as a function of temperature and combined to obtain an overall uncertainty on the thermal conductivity (product of thermal diffusivity by density and by specific heat) and on the thermoelectric figure of merit ZT. An increase with temperature of all these uncertainties is observed, in agreement with growing difficulties to measure these quantities when temperature increases. The uncertainties on the electrical resistivity and thermal diffusivity are most likely dominated by the uncertainty on the sample dimensions. The temperature-averaged (300-700 K) relative standard uncertainties at the confidence level of $68 \%$ amount to $6 \%, 8 \%, 11 \%$, and $19 \%$ for the Seebeck coefficient, electrical resistivity, thermal conductivity, and figure of merit $Z T$, respectively. Thermal conductivity measurements appear as the least accurate. The moderate value of the temperature-averaged relative expanded (confidence level of 95\%) uncertainty of $17 \%$ on the mean of $Z T$ is essential in establishing $\mathrm{Co}_{0.97} \mathrm{Ni}_{0.03} \mathrm{Sb}_{3}$ as a high temperature standard n-type thermoelectric material. () 2015 AIP Publishing LLC. [http://dx.doi.org/10.1063/1.4905250]
\end{abstract}

\section{INTRODUCTION}

Many scientific works are currently dedicated to the search of efficient thermoelectric materials. These materials could indeed be used in thermoelectric generators, producing electric energy from waste heat in everyday life (exhaust gas in cars for instance) or from industrial technologies (steel production, glassworks, etc.). The efficiency of a thermoelectric generator depends, through Carnot's efficiency, on the temperature difference between the cold and hot sources. It is also governed, as a first approximation, by the dimensionless thermoelectric figure of merit of the materials defined as $Z T=\alpha^{2} \mathrm{~T} / \rho \lambda$ where $T$ is the absolute temperature, $\alpha$ is the Seebeck coefficient (or thermopower), $\rho$ is the electrical resistivity, and $\lambda$ is the total thermal conductivity. To be

\footnotetext{
a) Author to whom correspondence should be addressed. Electronic mail: eric.alleno@icmpe.cnrs.fr. Tel.: +33 1497812 37. Fax: +33 14978 1203.
}

effective, such a research effort requires reliable and accurate measurements of $Z T$.

In theory, ZT may be directly measured by Harman's method. ${ }^{1}$ However, this method shows several severe experimental constraints that are not easy to fulfill. For instance, experiments should be performed under strict adiabatic conditions. Moreover, this method depends critically on the quality of the electrical contacts between the probes and the sample. ${ }^{2}$ If these conditions are not fulfilled, the inaccuracy of the results may be high, making this method inadequate for a rapid and accurate prospection of materials $Z T$. For novel materials with unknown or less established properties, $Z T$ is commonly obtained by measuring individually the three quantities $\alpha, \rho$, and $\lambda$. To determine the level of relative uncertainty achieved in the measurement of $Z T$, it is therefore necessary to estimate separately the relative uncertainty of $\alpha, \rho$, and $\lambda$ before combining them. The resulting total relative uncertainty on $Z T$ then yields a quantitative estimation of the reliability and accuracy of the measurement method. 
A round robin test (RRT) performed by several laboratories on any method of measurement of a given quantity is a statistical test that provides a standard deviation for this quantity. According to the "Guide to the Expression of Uncertainty in Measurement" (GUM) authored by the Joint Committee for Guides in Metrology (JCGM) from the Bureau International des Poids et Mesures (BIPM), ${ }^{3}$ such standard deviation is an estimate of the "Type A" uncertainty for this measured quantity. More didactic texts ${ }^{4-6}$ than "GUM" give practical examples of the determination of the experimental uncertainty. A RRT is also an individual test bench for any participating laboratory providing a diagnostic on its measurement methods.

A RRT on electrical resistivity, Seebeck coefficient, thermal conductivity, and figure of merit requires a common standard material for all these quantities. Reference materials certified by suppliers such as NIST (National Institute for Standard and Technology, USA) exist for electrical resistivity and thermal conductivity (Stainless steel NIST standard reference material (SRM) 1460 for instance) on the one hand, and Seebeck coefficient $\left(\mathrm{Bi}_{2} \mathrm{Te}_{3}\right.$ NIST SRM 3451) on the other hand. But a SRM for the three transport coefficient $(\alpha, \rho, \lambda)$ and the resulting figure of merit all together, either at low or at high temperature, remains to be established. For this reason, measurements on thermoelectric materials are more delicate and past RRT were conducted either on metals with well known physical properties (constantan, ${ }^{7-9}$ palladium ${ }^{7}$ ), on home-made thermoelectric materials $\left(\right.$ skutterudite $^{7}$ ), or materials supplied by a commercial source (bismuth telluride based materials ${ }^{8-11}$ ) but rarely on a reference material (Stainless steel NIST SRM 1460 for thermal diffusivity in Ref. 7). Moreover, a complete investigation, aiming to determine $Z T$ through the conduction of five separate measurements (Seebeck coefficient, electrical resistivity, density, specific heat, and diffusivity), was presented only recently ${ }^{10,11}$ by several laboratories from four countries. The measurements were performed from 300 to $500 \mathrm{~K}$ using hot-pressed $n$ - and $p$-type bismuth telluride materials commercially supplied (Marlow Industries). Part $\mathrm{I}^{10}$ of this study was focused on electrical resistivity and Seebeck coefficient only while part II $^{11}$ was dedicated to the thermal properties and final evaluation of $Z T$. From analyses of the results, it was concluded that the thermal conductivity is the least reliable measurement of the three transport properties involved in $Z T$.

In this paper, we report on a complete thermoelectric round robin testing, i.e., electrical resistivity, Seebeck coefficient, and thermal properties measurements between 300 and $700 \mathrm{~K}-\mathrm{a}$ temperature range broader than Refs. 10 and $11-$ in a $n$-type thermoelectric material based on a $\mathrm{CoSb}_{3}$ skutterudite. We selected this material for several reasons. First, $\mathrm{CoSb}_{3}$ skutterudite crystallizes in a cubic crystal lattice which enables the measurement of samples with various geometries obtained from the same batch and excludes any influence of anisotropy as observed in state-of-the-art thermoelectric compounds such as bismuth telluride. ${ }^{10,11}$ Second, $\mathrm{CoSb}_{3}$ is easy to synthesize in a reproducible way and shows good mechanical properties (easy to handle). In this context, we propose that this skutterudite may become a reference thermoelectric material in the near future. The paper is organized in the following way. The first part describes the experimental procedure to produce the materials and the set-ups used by the participating laboratories. The statistical tools used to analyze the experimental data are introduced in the second part while the measurement survey is presented in the third part. The survey includes ten laboratories from three countries (one Czech, eight French, and one Swiss) actively involved in thermoelectric research.

\section{EXPERIMENTAL DETAILS}

A polycrystalline sample of $\mathrm{Co}_{0.97} \mathrm{Ni}_{0.03} \mathrm{Sb}_{3}(\sim 65 \mathrm{~g})$ was prepared by melting the elements (Co $99.99 \%$, Ni 99.99\%, Sb $99.999 \%$ ) in stoichiometric quantity at $1100^{\circ} \mathrm{C}$ during 12 $\mathrm{h}$ followed by annealing at $820^{\circ} \mathrm{C}$ during $96 \mathrm{~h}$ in a quartz crucible sealed in a quartz tube placed in a vertical furnace. To ensure a good chemical homogeneity, the sample was powdered, mixed, and further annealed under the same conditions. This procedure was repeated three times. Sample quality was checked by means of powder X-ray diffraction (PXRD, Brucker D8, Cu K $\alpha$ ) performed at the top, middle, and bottom of the $\sim 7 \mathrm{~cm}$ long sample (see Fig. 1). Rietveld refinements against the PXRD patterns were carried out to determine the lattice parameter $a$ and the content of secondary phases. Only $1 \% \mathrm{CoSb}_{2}$ (mass percentage) and $0.2 \%$ metastable cubic $\mathrm{Sb}$ were detected as impurity phases. ${ }^{12}$ The lattice parameters obtained on the top, middle, and bottom of the ingot were $9.0403 \AA, 9.0405 \AA, 9.0408 \AA$, respectively. The standard deviation between these three values $\left(\sigma(a)= \pm 2.5 \times 10^{-4} \AA\right)$ is comparable to the experimental repeatability $(r p(a) \sim \pm 3$ $\times 10^{-4} \AA$ obtained by measuring the same sample several times with the same diffractometer, see below for a more extensive definition) which evidences the good chemical homogeneity of the sample.

The ingot was cut with cutting pliers (keeping only $54 \mathrm{~g}$ of the inner part to leave aside its extreme parts), finely ground using a planetary ball mill (for $5 \mathrm{~min}$ in a $\mathrm{ZrO}_{2}$ vial), and passed through a $50 \mu \mathrm{m}$ sieve. This powder was divided into 13 batches of approximately $4 \mathrm{~g}$, which were subsequently densified by Spark Plasma Sintering (SPS, Syntex DR SINTER Lab $515 \mathrm{~S}$ system) in graphite dies and punches $(\varnothing 10 \mathrm{~mm})$ for $10 \mathrm{~min}$ at $620^{\circ} \mathrm{C}$ under $50 \mathrm{MPa}$. All the cylindrical specimens of $\mathrm{Co}_{0.97} \mathrm{Ni}_{0.03} \mathrm{Sb}_{3}$ showed a relative density of $\sim 98 \%$ ( $\sim 6 \mathrm{~mm}$ long and $10 \mathrm{~mm}$ wide). One cylindrical sample-shown in Fig. 2-was sent to each participant of the RRT and was left free to be cut and/or polished into bars or disks to dimensions

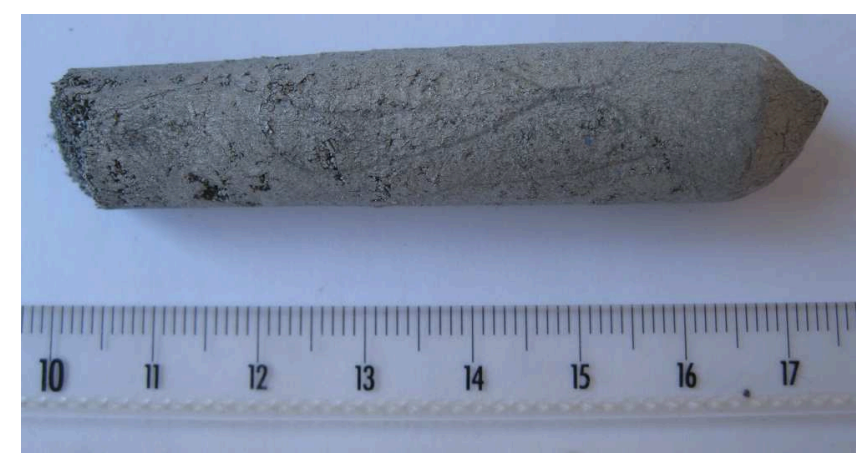

FIG. 1. Photograph of the as-cast sample. 


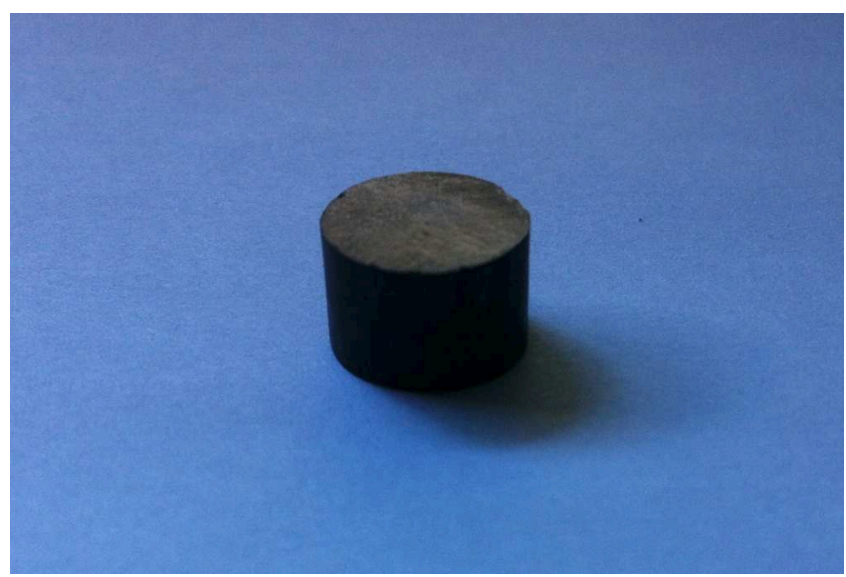

FIG. 2. Photograph of one of the shaped samples. Note that the picture was taken after few measurement cycles at $800 \mathrm{~K}$ by one of the participating labs.

appropriate to each measurement systems. Centralizing the cutting in a single location as in Refs. 10 and 11 would have certainly led to smaller $\mathrm{u}\left(x_{i}\right)$ but such procedure would not have corresponded to a usual research practice: labs synthesize or receive from other labs samples in various shapes and cut them themselves before measurements.

The high-temperature Seebeck coefficient and electrical resistivity were measured by 9 and 10 laboratories, respectively. Six home-made systems and four commercial systems (three ULVAC ZEM3 and one Ozawa Science RZ2001i) were used in this RRT. Four of the home made systems are described in detail in Refs. 12-17. To summarize these techniques, a differential method was systematically employed to measure the Seebeck coefficient in either the "two-probe" or the "fourprobe" geometry in three and six cases, respectively (methods and geometries of Seebeck coefficient measurements can be found in Refs. 2, 18, and 19). Bar-shaped samples, slabs in the van der Pauw geometry or in the linear four-probe geometry, were measured in six, two, and one cases, respectively. Six laboratories were able to measure the thermal diffusivity $(a)$ by the laser-flash method using commercial systems (four Netzsch LFA457, one Netzsch LFA427, and one Linseis LFA1000). The thermal conductivity was calculated from the thermal diffusivity by using the relation $\lambda=a \times d$ $\times C_{p}$, where $d$ is the density and $C_{p}$ is the specific heat, which was measured by the six laboratories using commercial calorimeters (a Quantum Design PPMS, two Netzsch DSC STA 449 F3 Jupiter, three Netzsch DSC 404 C Pegasus). All these transport and thermal measurements were carried out under an inert atmosphere (argon or helium). All the "raw" data reported by the participating laboratories were anonymously compiled and interpolated by cubic splines every $20 \mathrm{~K}$ for the Seebeck coefficient and electrical resistivity over the respective temperature intervals $[300 \mathrm{~K}-700 \mathrm{~K}]$ and $[300-760 \mathrm{~K}]$ and every $50 \mathrm{~K}$ for the thermal diffusivity, density, specific heat, thermal conductivity, and $Z T$ over the respective temperature intervals $[300 \mathrm{~K}-800 \mathrm{~K}],[300 \mathrm{~K}-800 \mathrm{~K}],[300 \mathrm{~K}-800 \mathrm{~K}]$, [300 K-800 K], and [300 K-700 K]. Interpolation of the data was preferred over parameterization (see an example in Ref. 8) because it does not modify the measured values which are considered as "reference datapoints."

\section{DEFINITION OF THE UNCERTAINTIES}

A complete set of data for the measured quantity $x$, representing $\alpha, \rho, a, d, C_{p}, \lambda$, or ZT, consists in $m$ series of interpolated values $x_{i}$ at temperature $T_{i}$, where $m$ is the number of participating laboratories. The index $i$ labels the equally spaced temperatures starting at $T_{1}, \ldots, T_{i}, \ldots$, and ending at $T_{n}, n$ being the number of temperatures. At each temperature $T_{i}$, an average $\left\langle x_{i}\right\rangle^{m}$ and an experimental standard deviation $\sigma\left(x_{i}\right)^{\mathrm{m}}$ of the measured quantity $x$ was calculated over the range (labeled by $p$ ) of all the $m$ participating laboratories according to the following formulae: $\left\langle x_{i}\right\rangle^{m}=\frac{1}{m} \sum_{p=1}^{m} x_{p i}$ and $\sigma\left(x_{i}\right)^{m}=\sqrt{\frac{1}{m-1}} \sqrt{\sum_{p=1}^{m}\left(x_{p i}-\left\langle x_{i}\right\rangle\right)^{2}}$. This means that only one measurement per laboratory was randomly taken into account despite the fact that several laboratories repeated their measurement. This strict procedure was chosen to give an equal statistical weight to each laboratory. This strategy avoids the possible bias consisting in including several sets of data from one laboratory, whose measurements are close to the average, in order to artificially reduce the standard deviation. We further assumed that the measurements follow a normal distribution around the average. At each temperature $\mathrm{T}_{\mathrm{i}}$, the measurement $x_{\mathrm{pi}}$ of each laboratory was then compared to the classical values $\left\langle x_{i}\right\rangle^{m}+2 \sigma\left(x_{i}\right)^{m}$ and $\left\langle x_{i}\right\rangle^{m}-2 \sigma\left(x_{i}\right)^{m}$ to stress possible aberrant measurements with a confidence interval of $95 \%$. For a given laboratory $p$, if one datum at temperature $T_{i}$ was found outside this interval, its whole set of data was excluded. Note that this procedure, which can be applied only once, complies with Chauvenet's criterion. ${ }^{6}$ Final average and standard deviation were then recalculated according to $\left\langle x_{i}\right\rangle^{r}=\frac{1}{r} \sum_{p=1}^{r} x_{p i}$ and $\sigma\left(x_{i}\right)^{r}=\sqrt{\frac{1}{r-1}} \sqrt{\sum_{p=1}^{r}\left(x_{p i}-\left\langle x_{i}\right\rangle\right)^{2}}$ where $r=m-q$ is the number of non-excluded laboratories and $q$ is the number of excluded laboratories.

At a given temperature $T_{i}$, four uncertainties can be defined: $u\left(x_{i}\right)$ and $u\left(\left\langle x_{i}\right\rangle\right)$, the standard uncertainty ${ }^{3,5}$ on the quantity $x_{i}$ and on its mean $\left\langle x_{i}\right\rangle$, respectively; $U\left(x_{i}\right)$ and $U\left(\left\langle x_{i}\right\rangle\right)$, the expanded uncertainty ${ }^{3,5}$ on $x_{i}$ and on its mean $\left\langle x_{i}\right\rangle$, respectively. $u\left(x_{i}\right)$ is defined ${ }^{3,5}$ by $u\left(x_{i}\right)=\sigma\left(x_{i}\right)^{r}$. Still assuming that the distribution is normal, $u\left(x_{i}\right)$ is the uncertainty at a confidence level of $68 \%$ (one standard deviation) for any individual measurement of the quantity $x_{i}$. In other words, this means that the "true" value for any $x_{i}$ measured in $\mathrm{Co}_{0.97} \mathrm{Ni}_{0.03} \mathrm{Sb}_{3}$ made by any of the $r$ laboratories involved in the present work has $68 \%$ of chances to be found in the interval $\left[x_{i}-u\left(x_{i}\right) ; x_{i}+u\left(x_{i}\right)\right]$. To reach a confidence level of $95 \%$, the expanded uncertainty $U\left(x_{i}\right)$ is correspondingly defined as $U\left(x_{i}\right)=t_{r-1} u\left(x_{i}\right)$ with $\mathrm{t}_{\mathrm{r}-1}$, the coverage factor. Because of the reduced number of laboratories $(<10), \mathrm{t}_{\mathrm{r}-1}$ is not taken equal to 2 but is taken equal to the student's tvalue for $r-1$ degrees of freedom and a confidence level of $95 \%$ (Ref. 6). $U\left(x_{i}\right)$ thus depends on $u\left(x_{i}\right)$ only by a factor independent on $T_{i} . u\left(x_{i}\right)$ can safely be interpreted as the uncertainty on $x_{i}$ by any of the $r$ laboratories-hence independent on the laboratory-measuring a thermoelectric material with properties similar to $\mathrm{n}$-type $\mathrm{Co}_{0.97} \mathrm{Ni}_{0.03} \mathrm{Sb}_{3}$ in the same 
temperature range ([300-700 K $]$ ). But considering this quantity as faithfully representing the uncertainty on any thermoelectric measurements carried out on any thermoelectric materials by any laboratory in the world would be a reckless extrapolation. Comparison with other RRTs ${ }^{10,11}$ nonetheless suggests that $u\left(x_{i}\right)$ can be considered as a crude estimate. $u\left(x_{i}\right)$ should not be confused with the repeatability $r p\left(x_{i}\right)$, which is defined as the "closeness of the agreement between repeated measurements of the same property under the same conditions." $r p\left(x_{i}\right)$ should individually be determined by each laboratory by repeating several times the measurement of $x_{i}$ on the same sample with the same experimental system (not yet done by most of us). The repeatability $r p\left(x_{i}\right)$ depends on the laboratory and is usually smaller than the standard uncertainty $u\left(x_{i}\right) . r p\left(x_{i}\right)$ can for instance be used by the laboratory to decide if two close values of $x$ measured with the same system, $x_{i}^{1}$ and $x_{i}^{2}$, can be considered as same $\left(\left|x_{i}^{1}-x_{i}^{2}\right| \leq 2 r p\left(x_{i}\right)\right)$ or different $\left(\left|x_{i}^{1}-x_{i}^{2}\right|>2 r p\left(x_{i}\right)\right)$.

The standard uncertainty $u\left(\left\langle x_{i}\right\rangle\right)$ on the mean $\left\langle x_{i}\right\rangle$ is defined $^{3,5}$ by $u\left(\left\langle x_{i}\right\rangle\right)=\frac{\sigma\left(x_{i}\right)^{r}}{\sqrt{r}}$. Similarly to $x_{i}$, an expanded uncertainty $U\left(\left\langle x_{i}\right\rangle\right)$ at the confidence level of $95 \%$ can also be defined using the student's t-value $\mathrm{t}_{\mathrm{r}-1}$ as the coverage factor: $U\left(\left\langle x_{i}\right\rangle\right)=t_{r-1} u\left(\left\langle x_{i}\right\rangle\right) .\left\langle x_{i}\right\rangle$ is an estimator of the "true value" of the quantity $x$ measured at $T_{i}$ in the sample $\mathrm{Co}_{0.97} \mathrm{Ni}_{0.03} \mathrm{Sb}_{3}$ used in the present work by the $r$ laboratories all together. Similarly, $U\left(\left\langle x_{i}\right\rangle\right)$ represents the expanded uncertainty on the "true value" of the quantity $x$ measured at $T_{i}$ in the sample $\mathrm{Co}_{0.97} \mathrm{Ni}_{0.03} \mathrm{Sb}_{3}$. The true value of the quantity $x$ measured at $T_{i}$ in $\mathrm{Co}_{0.97} \mathrm{Ni}_{0.03} \mathrm{Sb}_{3}$ has $95 \%$ chances to be found in the interval $\left\langle x_{i}\right\rangle \pm U\left(\left\langle x_{i}\right\rangle\right)$. As will be seen further in this text, the reduced magnitude of the relative expanded uncertainties $\frac{U(\langle x\rangle)}{\langle x\rangle}$ will establish $\mathrm{Co}_{0.97} \mathrm{Ni}_{0.03} \mathrm{Sb}_{3}$ as a reference standard.

Since for any measured quantity $x$, each $u\left(x_{i}\right)$ is expressed at the same confidence level (68\%) independently on $x$ and regardless of the number of non-excluded participating laboratories, they can consistently be combined to calculate the overall uncertainties on the dimensionless figure of merit and the thermal conductivity. The relative uncertainty on $\lambda$ originates from the relative uncertainties on $a, C_{v}$, and $d$. According to Refs. $3-6$, the related relative uncertainty is given by $\frac{u\left(\lambda_{i}\right)}{\lambda_{i}}$ $=\sqrt{\left(\frac{u\left(a_{i}\right)}{\left\langle a_{i}\right\rangle}\right)^{2}+\left(\frac{u\left(d_{i}\right)}{\left\langle d_{i}\right\rangle}\right)^{2}+\left(\frac{u\left(C_{v i}\right)}{\left\langle C_{v i}\right\rangle}\right)^{2}}$. Noteworthy, $u\left(\lambda_{i}\right)$ is not derived here from the standard deviation on $\lambda_{i}$. Similarly, the relative uncertainty on $Z T$ is related to the relative uncertainties on $\alpha, \rho$, and $\lambda$ by $\frac{u\left(Z T_{i}\right)}{Z T_{i}}=\sqrt{4\left(\frac{u\left(\alpha_{i}\right)}{\left\langle\alpha_{i}\right\rangle}\right)^{2}+\left(\frac{u\left(\rho_{i}\right)}{\left\langle\rho_{i}\right\rangle}\right)^{2}+\left(\frac{u\left(\lambda_{i}\right)}{\left\langle\lambda_{i}\right\rangle}\right)^{2}}$. Finally, for a given quantity $x$, its relative uncertainty can be averaged over the whole temperature range by the equation $\left\langle\frac{u(x)}{\langle x\rangle}\right\rangle_{T}=\frac{1}{n} \sum_{i=1}^{n} \frac{u\left(x_{i}\right)}{\left\langle x_{i}\right\rangle}$ (with $\mathrm{n}$ the number of measurement temperatures). This formula provides a single number easy to compare, memorize, and use. The three former formulae of course apply to $U(x), u\left(\left\langle x_{i}\right\rangle\right)$, and $U(\langle x\rangle)$. All the values obtained for $\alpha, \rho, \lambda$, and $Z T$ are listed in Table II.

\section{RESULTS}

\section{Seebeck coefficient}

Over the $m=9$ laboratories that measured the Seebeck coefficient $\alpha$ in $\mathrm{Co}_{0.97} \mathrm{Ni}_{0.03} \mathrm{Sb}_{3}$ as a function of temperature

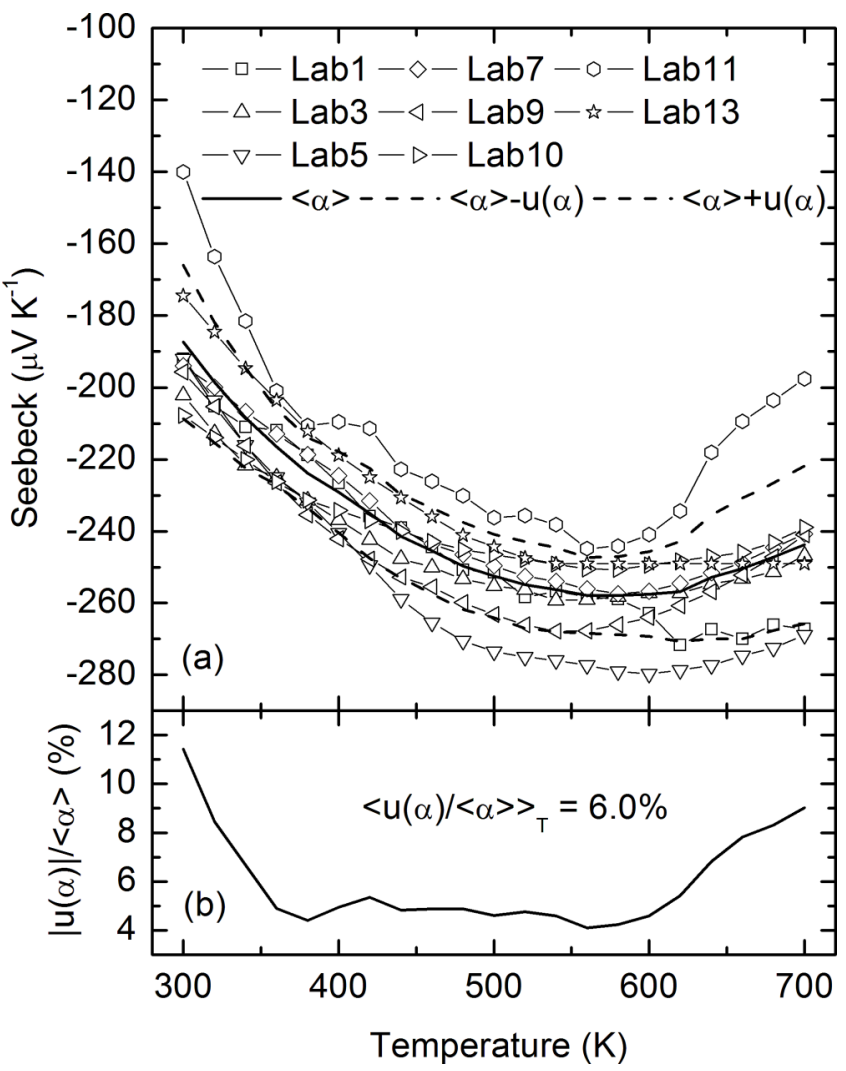

FIG. 3. Panel (a): Seebeck coefficient measured by the various participating laboratories as a function of temperature in $\mathrm{Co}_{0.97} \mathrm{Ni}_{0.03} \mathrm{Sb}_{3}$. These data are compared to the average and to the absolute standard uncertainty. Panel (b): Standard relative uncertainty on the Seebeck coefficient as a function of temperature.

between $300 \mathrm{~K}-700 \mathrm{~K}, q=1$ laboratory was excluded because of aberrant measurements. The data of the eight remaining laboratories are presented in Fig. 3. Both the magnitude and the temperature dependence of $\alpha$ are typical of heavily doped semiconductors, in agreement with prior studies. ${ }^{20-23}$ The average room-temperature value $(-187 \mu \mathrm{V} / \mathrm{K})$ compares well with the value $(-200 \mu \mathrm{V} / \mathrm{K})$ published by Anno et al. ${ }^{20}$ for the same nominal composition. The data of six laboratories fall within the interval $\langle\alpha\rangle-u(\alpha)$ and $\langle\alpha\rangle+u(\alpha)$ in the entire temperature range.

The absolute value of the relative standard uncertainty $\frac{u(\alpha)}{\langle\alpha \alpha\rangle}$ is also shown in Fig. 3 as a function of temperature. The observed values are constant and slightly below $5 \%$ between 340 and $600 \mathrm{~K}$ while a steeper rise occurs above $600 \mathrm{~K}$ to reach $9 \%$ at $700 \mathrm{~K}$. These $5 \%$ at $340 \mathrm{~K}$ compare well to the $\frac{\sigma(\alpha)}{\langle\alpha\rangle}= \pm 4 \%$ determined in Ref. 8 at $300 \mathrm{~K}$ in the NIST standard material SRM3451 $\mathrm{Bi}_{2} \mathrm{Te}_{3}$. The thermal variations in the uncertainty $u(\alpha)$ (not shown) are very similar to those of $\frac{u(\alpha)}{\langle\alpha\rangle \mid}$. The increase in $\frac{u(\alpha)}{\langle\alpha \alpha\rangle}$ is thus not related to the moderate decrease in $|\langle\alpha\rangle|$ above $600 \mathrm{~K}$. The average value over the $300-700 \mathrm{~K}$ temperature range of the relative standard uncertainty is $\left\langle\frac{u(\alpha)}{\langle\alpha\rangle}\right\rangle_{T}= \pm 6.0 \%$.

\section{Electrical resistivity}

Ten $(m=10)$ laboratories measured the electrical resistivity $\rho$ in $\mathrm{Co}_{0.97} \mathrm{Ni}_{0.03} \mathrm{Sb}_{3}$ as a function of temperature 
between $300 \mathrm{~K}-800 \mathrm{~K}$. One $(q=1)$ laboratory was excluded because of aberrant measurements. The remaining data $(r=9)$ are presented in Fig. 4 and compared to $\langle\rho\rangle,\langle\rho\rangle-u(\rho)$, and $\langle\rho\rangle+u(\rho)$. The decrease in $\rho$ when the temperature rises is consistent with the semiconducting nature of this sample. The average value $\langle\rho\rangle$ at $300 \mathrm{~K}\left(3.3 \times 10^{-5} \Omega \mathrm{m}\right)$ is slightly larger than the value $\left(2.9 \times 10^{-5} \Omega \mathrm{m}\right)$ found by Anno et al. ${ }^{20}$ for the same nominal composition. We surmise that the initial purity of the starting elements and the density of our sample weakly differ from literature,${ }^{20}$ thereby explaining the observed difference.

The electrical resistivity measurement is the product ${ }^{2,18}$ of a temperature dependent resistance $R(T)$ and a constant (neglecting thermal expansion) geometrical form factor $g$ which has the dimension of a length: $\rho(T)=g R(T) . R$ is obtained from voltage and current measurements while $g$ is obtained from sample dimensions measurements. Therefore, the normalized data $\frac{\rho(T)}{\rho(300 K)}=\frac{R(T)}{R(300 K)}$ only depend on electrical measurements and do not depend on the geometrical form factor. As shown in panel (b) of Fig. 4, the normalized data $\frac{\rho(T)}{\rho(300 K)}$ of six laboratories (lab1, lab2, lab3, lab7, lab9, lab13) out of nine almost merge into a single curve. The electrical measurements $R(T)$ of these six laboratories are, hence, almost identical and the differences between their $\rho(T)$ measurements

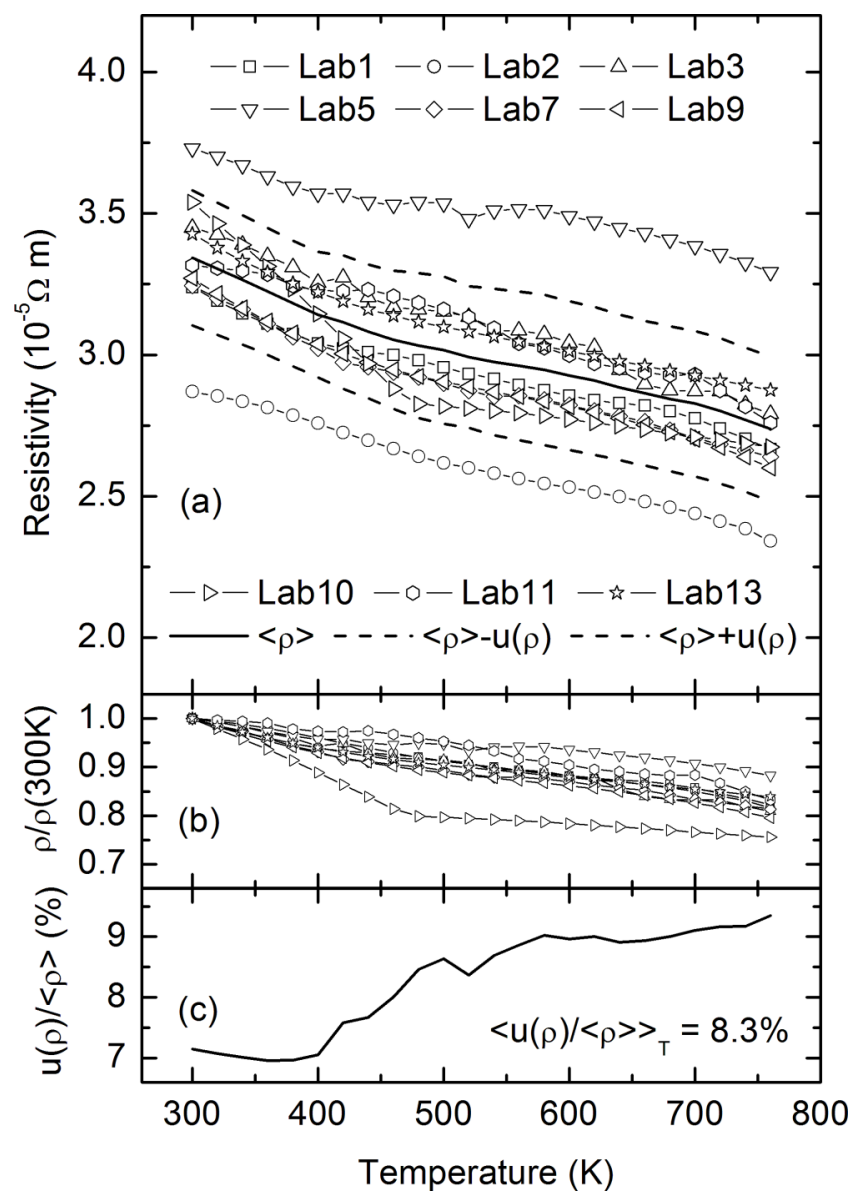

FIG. 4. Panel (a): Electrical resistivity measured by the various participating laboratories as a function of temperature in $\mathrm{Co}_{0.97} \mathrm{Ni}_{0.03} \mathrm{Sb}_{3}$. These data are compared to the average and to the absolute standard uncertainty. Panel (b): Normalized resistivity as a function of temperature. Panel (c): Relative standard uncertainty on the resistivity as a function of temperature. (panel (a) of Fig. 4) reflect the uncertainty on the measurement of the geometrical factor. This indicates that for these six laboratories, the main source of uncertainty on $\rho(T)$ arises from a poorly controlled shape (beveled edges), from inaccurate measurements of the dimensions of the samples or of distances between the voltage probes. For the other three laboratories (lab5, lab10, lab11), the difference of their normalized data $\frac{R(T)}{R(300 \mathrm{~K})}$ differs from the common normalized curve indicating that an extra source of uncertainty on their $R(T)$ measurements adds to the uncertainty on $g$. Since the difference between their normalized data tends to increase with temperature, this extra source of uncertainty might be related to a contamination of the Ohmic voltage by spurious thermal voltages: ${ }^{2,18}$ with increasing temperature, temperature differences usually increase in the system of measurement possibly giving rise to partially uncompensated thermal voltages even upon current reversal.

The relative standard uncertainty $\frac{u(\rho)}{\langle\rho\rangle}$, shown in Figure 4 as a function of temperature, is equal to $\sim 7 \%$ between 300 and $400 \mathrm{~K}$ before increasing from $400 \mathrm{up}$ to $600 \mathrm{~K}$ to reach $\sim 9 \%$. Above this temperature, the relative uncertainty no longer varies with temperature. These variations reflect the thermal variations in the absolute uncertainty $u(\rho)$ (not shown) and are thus not related to the decrease in $\langle\rho\rangle$ with temperature. The average value over the $300-760 \mathrm{~K}$ temperature range of the relative standard uncertainty is $\left\langle\frac{u(\rho)}{\langle\rho\rangle}\right\rangle_{T}= \pm 8.3 \%$. As previously discussed, this uncertainty can be decomposed into an uncertainty on the geometrical form factor $\left(\frac{u(\rho)_{g e o}}{\langle\rho\rangle}=\frac{u(g)}{\langle g\rangle}\right)$ and an uncertainty gathering the electrical and thermal effects $\left(\frac{u(\rho)_{\text {ideal }}}{\langle\rho\rangle}=\frac{u(R)}{\langle R\rangle}\right)$. Assuming that the normalized resistivities are free from any geometrical effect, $\frac{u(\rho)_{\text {ideal }}}{\langle\rho\rangle}$ can thus be obtained from $u(\rho)_{\text {ideal }}=\sigma\left(\rho_{\text {norm }}\right)^{r}$ and $\frac{u(\rho)_{\text {geo }}}{\langle\rho\rangle}$ can be derived

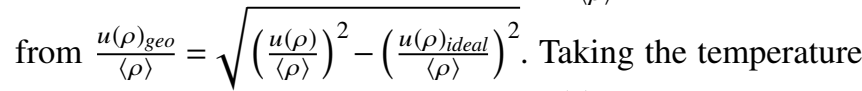
average over $300 \mathrm{~K}-760 \mathrm{~K}$ leads to $\left\langle\frac{u(\rho)_{\text {ideal }}}{\langle\rho\rangle}\right\rangle_{T}= \pm 3.7 \%$ and $\left\langle\frac{u(\rho)_{\text {geo }}}{\langle\rho\rangle}\right\rangle_{T}= \pm 7.3 \%$. This confirms the well-known result that uncertainties on the various measured dimensions dominate the uncertainty on resistivity.

As a final check of the sample homogeneity after shaping, cut parts of all the samples formerly dispatched among the labs were gathered in one of the participating lab (Institut Jean Lamour, Nancy) and re-measured at room temperature with a single system (ULVAC ZEM3). Electrical resistivity is the transport property which is the most sensitive to variations of microstructure across a population of samples and should reveal any sample-to-sample non-uniformity after shaping. One measurement was performed on each of the $r=9$ samples and the resulting mean $\left\langle\rho_{\text {check }}\right\rangle$ and standard deviation $\sigma\left(\rho_{\text {check }}\right)$ were gathered in Table I as well as repeatability data $\left(\left\langle\rho_{r p}\right\rangle\right.$ and $\left.r p(\rho)\right)$ obtained by measuring 3 times the same sample on the same system. The mean $\left\langle\rho_{\text {check }}\right\rangle=3.1 \times 10^{-5} \Omega \mathrm{m}$ is slightly different from the average $\langle\rho$ (at $300 \mathrm{~K}$ over the various 9 laboratories but falls within the uncertainty interval at this temperature $\left(3.3 \pm 0.24 \times 10^{-5} \Omega \mathrm{m}\right)$ while the repeatability mean $\left\langle\rho_{r p}\right\rangle=3.1 \times 10^{-5} \Omega \mathrm{m}$ is by chance equal to $\langle\rho\rangle$ at $300 \mathrm{~K}$. The relative repeatability of the experiment is $\frac{r p(\rho)}{\left\langle\rho_{r p}\right\rangle}=1.2 \%$ while the standard deviation on the 9 measurements is $\frac{\sigma(\rho)}{\left\langle\rho_{\text {check }}\right\rangle}$ 
TABLE I. Second row: Number of measurements, average electrical resistivity, absolute and relative repeatability of the electrical resistivity at $300 \mathrm{~K}$ in one of the samples used for the repeatability test; fourth row: Number of samples, average electrical resistivity, absolute and relative standard deviation at $300 \mathrm{~K}$ of the resistivity measured in nine different samples by one laboratory to check their homogeneity; sixth row: Number of laboratories, average electrical resistivity, absolute and relative standard deviation at $300 \mathrm{~K}$ of the electrical resistivity measured by the nine different laboratories in nine different samples.

\begin{tabular}{lccc}
\hline \hline $\mathrm{r}$ & $\left\langle\rho_{r p}\right\rangle(\Omega \mathrm{m})$ & $r p(\rho)(\Omega \mathrm{m})$ & $r p(\rho) /\left\langle\rho_{r p}\right\rangle(\%)$ \\
3 & $3.3 \times 10^{-5}$ & $\pm 4.0 \times 10^{-7}$ & \pm 1.2 \\
\hline $\mathrm{r}$ & $\left\langle\rho_{\text {check }}\right\rangle(\Omega \mathrm{m})$ & $\sigma\left(\rho_{\text {check }}\right)(\Omega \mathrm{m})$ & $\sigma\left(\rho_{\text {check }}\right) /\left\langle\rho_{\text {check }}\right\rangle(\%)$ \\
9 & $3.1 \times 10^{-5}$ & $\pm 9.7 \times 10^{-7}$ & \pm 3.1 \\
\hline $\mathrm{r}$ & $\langle\rho\rangle(300 \mathrm{~K})(\Omega \mathrm{m})$ & $u(\rho)(300 \mathrm{~K})(\Omega \mathrm{m})$ & $u(\rho) /\langle\rho\rangle(300 \mathrm{~K})(\%)$ \\
9 & $3.3 \times 10^{-5}$ & $\pm 2.4 \times 10^{-6}$ & \pm 7.1 \\
\hline \hline
\end{tabular}

$=3.1 \%$. It is slightly larger than twice the relative repeatability $\frac{r p(\rho)}{\left\langle\rho_{r p}\right\rangle}$ indicating a small non-uniformity of the electrical resistivity across the 9 tested samples. This non-uniformity value of $3.1 \%$ compares well with the $1.5 \%$ and $5.8 \%$ of sample-tosample non-uniformities found in p-type and n-type $\mathrm{Bi}_{2} \mathrm{Te}_{3}$, respectively, by Wang et al. in a past RRT. ${ }^{10}$ More importantly, $\frac{\sigma(\rho)}{\left\langle\rho_{\text {check }}\right\rangle}$ is much smaller than the relative uncertainty on electrical resistivity derived at $300 \mathrm{~K}$ from this RRT which amounts to $\frac{u(\rho)}{\langle\rho\rangle}(300 \mathrm{~K})=7.1 \%$. This last value does not arise from a spread of the transport properties across our tested population of samples and it is indeed a good estimate of the uncertainty on the measurements.

\section{Thermal diffusivity, specific heat, and thermal conductivity}

The thermal diffusivity $(a)$ data of the 6 participating laboratories (none excluded) obtained from the laser-flash technique are shown in Fig. 5(a). The data of four of the six laboratories strictly fall within $\langle a\rangle-u(a)$ and $\langle a\rangle+u(a)$. The diffusivities normalized at $400 \mathrm{~K}\left(a_{\text {norm }}(T)=\frac{a(T)}{a(400 \mathrm{~K})}\right)-$ see discussion below about this choice of temperaturedisplayed in Fig. 5(b) nearly merge into a single curve indicating that the six datasets are nearly homothetic. In the laser-flash technique, the thermal diffusivity is extracted from a least-squares fit to the entire transient curve from a model chosen between several possibilities (among them, "Parker,"24 "Cowan,"25 "Cape-Lehman"26). In the simplest approach, proposed by Parker et al. (no heat loss assumed and one dimensional heat flow), the thermal diffusivity is expressed as

$$
a(T)=\frac{1.37 l^{2}}{\pi^{2} t_{1 / 2}(T)}
$$

with $l$ the sample thickness and $\mathrm{t}_{1 / 2}$ a time characteristic of the transient temperature variations of the sample. ${ }^{24}$ One can see from this formula that the uncertainty on the diffusivity strongly depends on the uncertainty on the sample thickness (this remains true when using more sophisticated models). If we neglect the temperature variations in the dimensions of the sample, the thickness may be then considered as

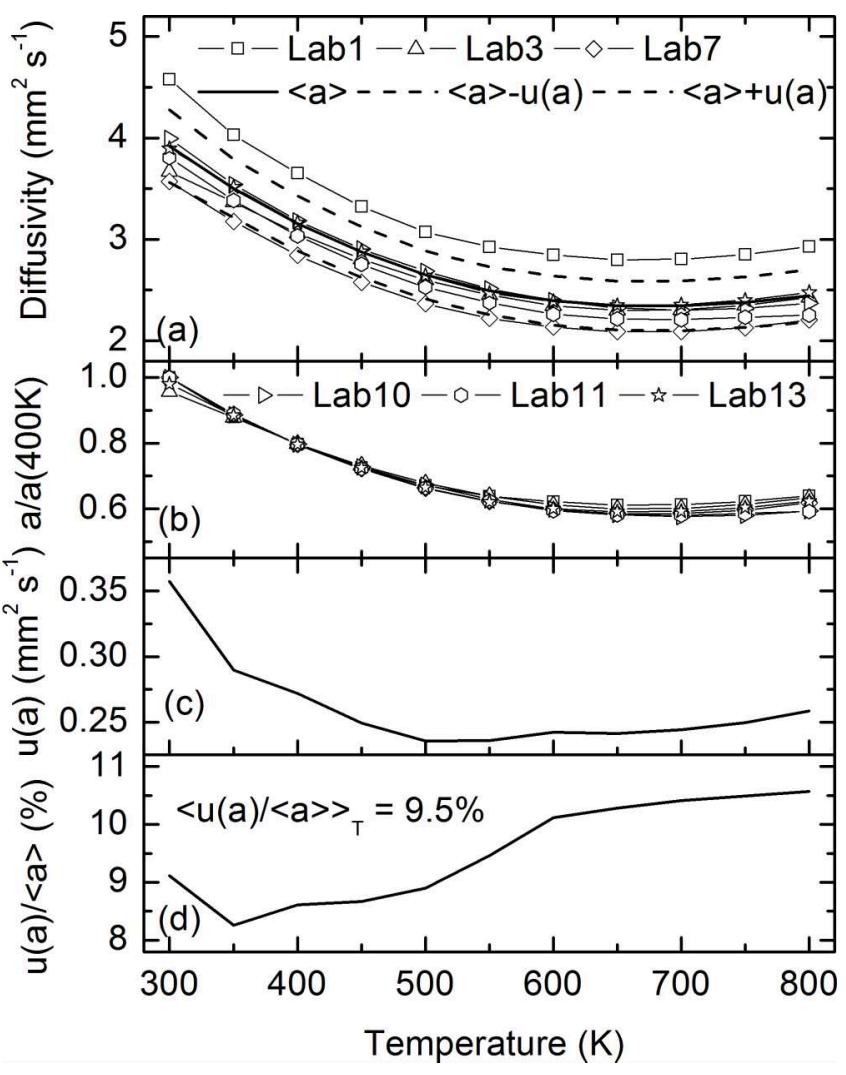

FIG. 5. Panel (a): Thermal diffusivity measured by the various participating laboratories as a function of temperature in $\mathrm{Co}_{0.97} \mathrm{Ni}_{0.03} \mathrm{Sb}_{3}$. These data are compared to the average and to the absolute standard uncertainty. Panel (b): Normalized thermal diffusivity as a function of temperature. Panels (c) and (d), respectively, absolute and relative standard uncertainty on the thermal diffusivity as a function of temperature.

temperature independent. The homothetic behavior of the normalized diffusivities may thus arise from the predominance of the uncertainty on the thickness with respect to the total uncertainty.

The absolute and the relative uncertainties on the thermal diffusivity are shown in Figures 5(c) and 5(d) as a function of temperature. The absolute uncertainty significantly decreases from 300 to $600 \mathrm{~K}$ while the relative uncertainty slightly increases from $\sim 9 \%$ to $10 \%$ within the same temperature range. These opposite variations arise from the decrease in the thermal diffusivity in this temperature range. The larger value of absolute uncertainty near $300 \mathrm{~K}$ could be related to the lower sensitivity of the detector (InSb for all laser-flash used in this RRT) around this temperature. To reduce the uncertainty at $300 \mathrm{~K}$, the power of the laser-flash setup should be carefully optimized to reach a higher signal-to-noise ratio. The diffusivity was therefore normalized at $400 \mathrm{~K}$ in Fig. 5(b) to avoid the $300 \mathrm{~K}$ datum. The average value over the $300-800 \mathrm{~K}$ temperature range of the relative standard uncertainty is $\left\langle\frac{u(a)}{\langle a\rangle}\right\rangle_{T}= \pm 9.5 \%$. Similar to resistivity measurements, this uncertainty can be decomposed into an uncertainty arising from the laser and detection chain $\frac{u(a)_{\text {ideal }}}{\langle a\rangle}$ which can be obtained from $\frac{u(a)_{\text {ideal }}}{\langle a\rangle}=\frac{\sigma\left(a_{\text {norm }}\right)^{r}}{\left\langle a_{\text {norm }}\right\rangle}$ and a geometrical uncertainty which can be derived from $\frac{u(a)_{\text {geo }}}{\langle a\rangle}=$ $\sqrt{\left(\frac{u(a)}{\langle a\rangle}\right)^{2}-\left(\frac{u(a)_{\text {ideal }}}{\langle a\rangle}\right)^{2}}$. Taking the temperature average over 
$300 \mathrm{~K}-800 \mathrm{~K}$ leads to $\left\langle\frac{u(a)_{\text {ideal }}}{\langle a\rangle}\right\rangle_{T}= \pm 1.6 \%$ and $\left\langle\frac{u(a)_{\text {geo }}}{\langle a\rangle}\right\rangle_{T}$ $= \pm 9.4 \%$. This suggests that reducing the uncertainty on the thickness - a moderately complex task - could lead to strong improvements of the accuracy of diffusivity measurements.

Three laboratories measured the density at room temperature while the three others considered the theoretical density $\left(7.6 \mathrm{~g} / \mathrm{cm}^{3}\right)$. The temperature independent average density is then $7.3 \mathrm{~g} / \mathrm{cm}^{3}$ and the corresponding absolute and relative standard uncertainties are $\pm 0.3 \mathrm{~g} / \mathrm{cm}^{3}$ and $4.3 \%$, respectively.

The six laboratories measured the specific heat $\left(\mathrm{C}_{\mathrm{p}}\right)$ as a function of temperature. The data plotted in Fig. 6 only slightly depend on temperature. The uncertainty on $C_{p}$ varies from $\sim 2 \%$ at $350 \mathrm{~K}$ to $3.0 \%$ at $800 \mathrm{~K}$. The average value over the $300-800 \mathrm{~K}$ temperature range of the relative uncertainty is $\left\langle\frac{u\left(C_{p}\right)}{\left\langle C_{p}\right\rangle}\right\rangle_{T}= \pm 2.5 \%$.

The thermal conductivity data are plotted in Fig. 6 as a function of temperature. Except for one laboratory, all the data curves fall within $\langle\lambda\rangle-u(\lambda)$ and $\langle\lambda\rangle+u(\lambda)$. The relative uncertainty increases from $\sim 10 \%$ at 300 to $\sim 12 \%$ at $800 \mathrm{~K}$. The temperature-averaged value of the relative standard uncertainty on thermal conductivity is $\left\langle\frac{u(\lambda)}{\langle\lambda\rangle}\right\rangle_{T}= \pm 10.8 \%$. This last value is in agreement with the temperature-averaged (300 $-475 \mathrm{~K}$ ) value of $\pm 12.5 \%$ derived from the RRT reported in Ref. 11. It also compares fairly well with the value directly

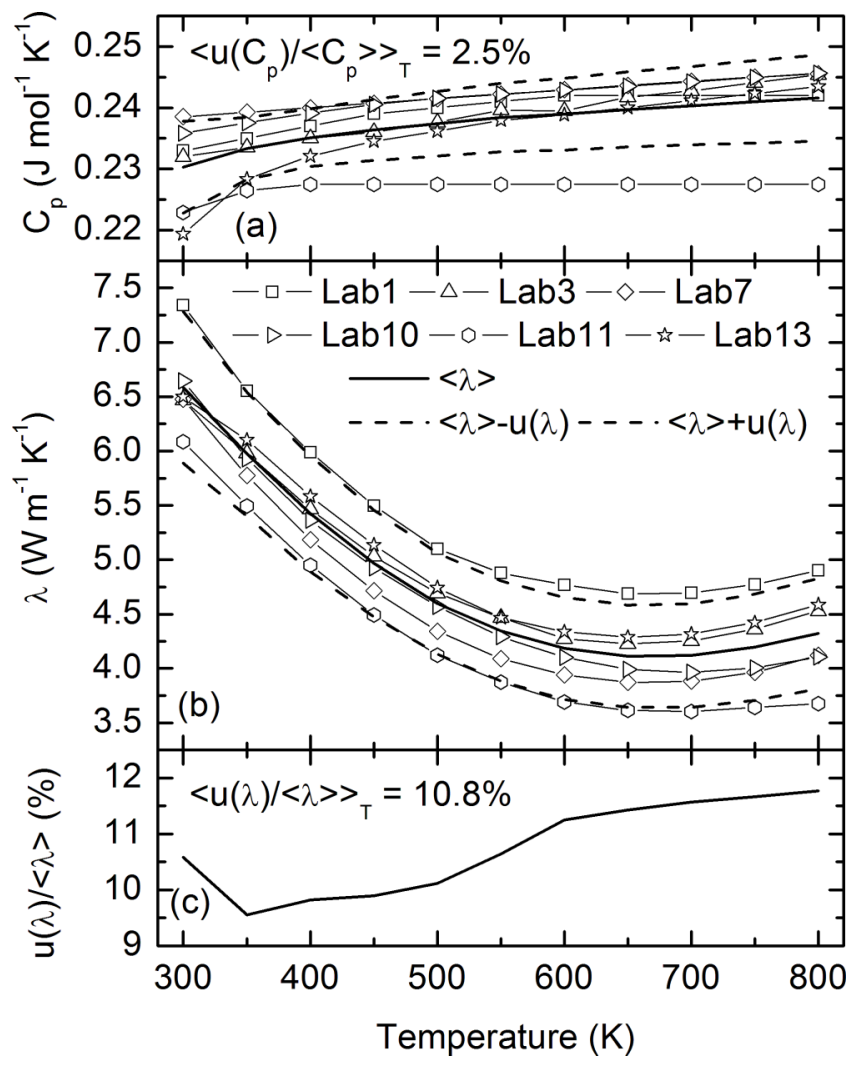

FIG. 6. Panel (a): Specific heat values measured by the various participating laboratories as a function of temperature in $\mathrm{Co}_{0.97} \mathrm{Ni}_{0.03} \mathrm{Sb}_{3}$. Panel (b): Thermal conductivity measured by the various participating laboratories as a function of temperature in $\mathrm{Co}_{0.97} \mathrm{Ni}_{0.03} \mathrm{Sb}_{3}$. These data are compared to the average and to the absolute standard uncertainty. Panel (c): Relative standard uncertainty on the thermal conductivity as a function of temperature. derived from the temperature-averaged relative standard deviation of the measured thermal conductivities: $\sum_{i=1}^{n} \frac{\sigma\left(\lambda_{i}\right)}{\lambda_{i}}$ $=8.0 \%$. However, this latter value is lower than the temperatureaveraged relative uncertainty on the diffusivity $( \pm 9.5 \%)$ and hence seems too optimistic. This effect likely arises from compensating errors. When compared to the uncertainties on Seebeck coefficient and resistivity, the uncertainty on thermal conductivity is the largest (nearly a factor of 2). Thermal conductivity measurement is thus the less accurate measurement, as expected and already noticed in Ref. 11.

An idealized temperature-averaged value of the uncertainty on the thermal conductivity $\left(\left\langle\frac{u(\lambda)_{\text {ideal }}}{\langle\lambda\rangle}\right\rangle_{T}\right)$, cleared from the geometrical uncertainty, can also be derived by replacing $\frac{u(a)}{\langle a\rangle}$ by $\frac{u(a)_{\text {ideal }}}{\langle a\rangle}$ in the formula giving $\frac{u(\lambda)}{\lambda}$ (see the part defining the uncertainties). This leads to $\left\langle\frac{u(\lambda)_{\text {ideal }}}{\langle\lambda\rangle}\right\rangle_{T}= \pm 5.3 \%$. In the ideal case, the uncertainties on the density and specific heat would dominate the uncertainty on the thermal conductivity.

\section{Figure of merit}

The dimensionless figures of merit of the six laboratories that measured the three quantities $\alpha, \rho$, and $\lambda$ are shown in Figure 7 as a function of temperature. Except one datum, all data fall within the interval $[Z T-u(Z T) ; Z T+u(Z T)]$. The averaged value of $Z T$ in $\mathrm{Co}_{0.97} \mathrm{Ni}_{0.03} \mathrm{Sb}_{3}$ increases from 0.05

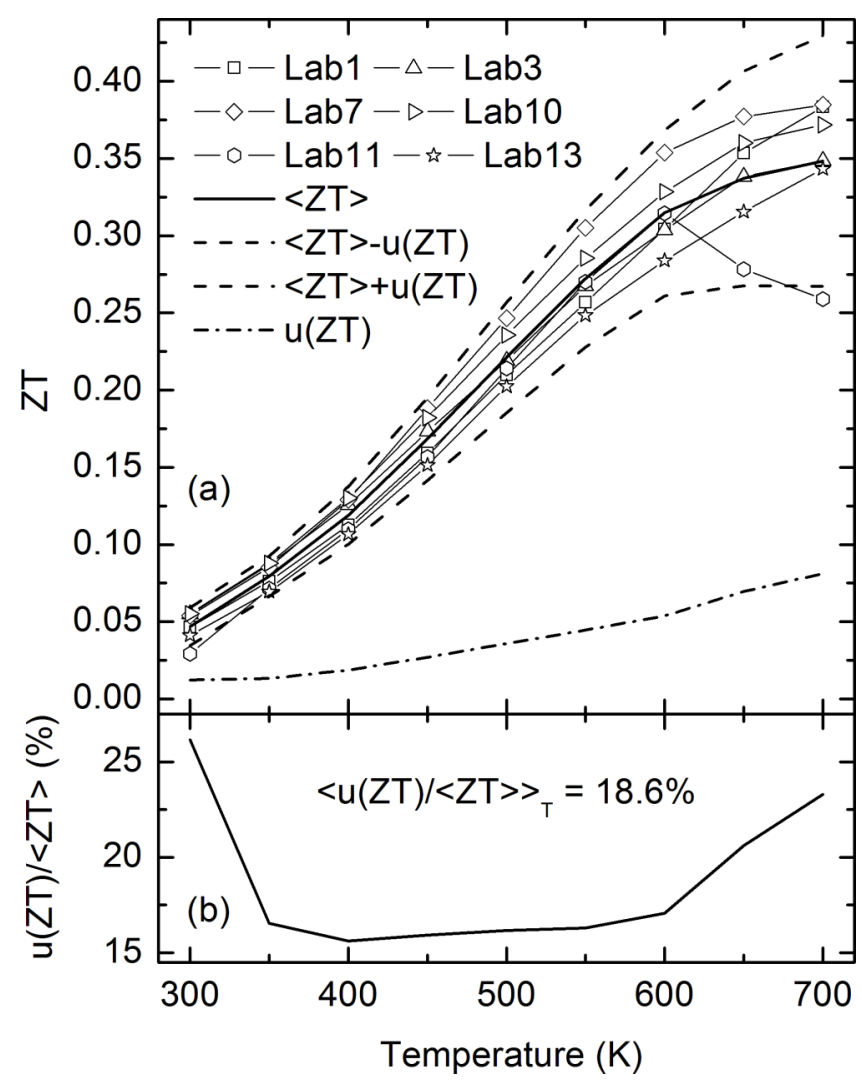

FIG. 7. Panel (a): Figure of merit measured by the various participating laboratories as a function of temperature in $\mathrm{Co}_{0.97} \mathrm{Ni}_{0.03} \mathrm{Sb}_{3}$. These data are compared to the average and to the absolute standard uncertainty. Panel (b): Relative standard uncertainty on the figure of merit as a function of temperature. 
at $300 \mathrm{~K}$ to 0.36 at $700 \mathrm{~K}$, as expected for an unfilled $n$-type skutterudite. The absolute uncertainty on $Z T(u(Z T)$ ) (see Figure 7) monotonically increases from 0.01 at $300 \mathrm{~K}$ to 0.08 at $700 \mathrm{~K}$. This is in line with the gross variations of $\frac{u(\alpha)}{\langle\alpha\rangle}$, $\frac{u(\rho)}{\langle\rho\rangle}$, and $\frac{u(\lambda)}{\langle\lambda\rangle}$ with temperature and reflects the difficulties to measure these quantities at high temperatures. $\frac{u(Z T)}{\langle Z T\rangle}$ starts from $\sim 25 \%$ at $300 \mathrm{~K}$ due to the unexpectedly large value of $u(Z T)$ at this temperature, remains constant at $\sim 16 \%$ between 350 and $600 \mathrm{~K}$ and eventually increases above $600 \mathrm{~K}$ owing to the increase in $u(Z T)$. The temperature-averaged value of the relative uncertainty on the figure of merit is $\left\langle\frac{u(Z T)}{\langle Z T\rangle}\right\rangle_{T}$ $= \pm 18.6 \%$. This latter value is in fair agreement with that reported in Ref. 11: $\pm 15.8 \%$ which is underestimated because derived from the standard deviation on $Z T$ - see below-and temperature-averaged over $300-475 \mathrm{~K}$ only. As expected, $\left\langle\frac{u(Z T)}{\langle Z T\rangle}\right\rangle_{T}$ is larger than the averaged value directly derived from the standard deviation on $Z T$, i.e., $\sum_{i=1}^{n} \frac{\sigma\left(Z T_{i}\right)}{Z T_{i}}=10.8 \%$. Likewise the discussion on the thermal conductivity, the latter value is too optimistic and arises from compensation of errors between the various measured quantities.

An uncertainty on the figure of merit cleared from the geometrical uncertainties on resistivity and thermal conductivity can also be defined by using $\frac{u(\rho)_{\text {ideal }}}{\rho}$ and $\frac{u(\lambda)_{\text {ideal }}}{\lambda}$ in its calculation. $\left\langle\frac{\left.u(Z T)_{\text {ideal }}\right\rangle}{\langle Z T\rangle}\right\rangle_{T}= \pm 14.3 \%$ is thus obtained. This value suggests that reducing the uncertainty on the thickness of the samples used in thermal diffusivity measurements is an easy first step on the path to reducing $u(Z T)$. As a slightly more complex second step, a reduction of $u(Z T)$ could be obtained by improving the accuracy of measurements of the dimensions (cross-section, voltage probes distance) involved in the measurement of resistivity. Given the dominant weight in $\frac{u(Z T)}{\langle Z T\rangle}$ of the uncertainty on the Seebeck coefficient which does not depend on measurements of dimensions, decreasing $\left\langle\frac{u(Z T)}{\langle Z T\rangle}\right\rangle_{T}$ below $10 \%$ will be a more demanding goal which will require strong improvements of the accuracy of the measurements of the Seebeck coefficient.

TABLE II. Temperature averaged relative uncertainties and statistical parameters used for the calculation of the expanded uncertainty on the Seebeck coefficient, the resistivity, the thermal conductivity, and the figure of merit. First row: Number $r$ of non-excluded laboratory; second row: Student $\mathrm{t}$-values corresponding to the number, $r-1$, of degrees of freedom at the confidence level of $95 \%$; third row: standard relative uncertainties on the quantity $x$ averaged over $300-700 \mathrm{~K}$; fourth row: expanded relative uncertainties (at 95\% confidence) on the quantity $x$ averaged over $300-700 \mathrm{~K}$; fifth row: standard relative uncertainties on the mean of the quantity $x$ averaged over 300-700 K; last row: expanded relative uncertainties (at 95\% confidence) on the mean of any quantity $x$ averaged over 300-700 K.

\begin{tabular}{lcccc}
\hline \hline & Seebeck & Resistivity & Thermal conductivity & ZT \\
\hline$r$ & 8 & 9 & 6 & 6 \\
$t_{r-1}$ & 2.36 & 2.31 & 2.57 & 2.57 \\
$\left\langle\frac{u(x)}{\langle x\rangle}\right\rangle_{T}(\%)$ & \pm 6.0 & \pm 8.3 & \pm 10.8 & \pm 18.6 \\
$\left\langle\frac{U(x)}{\langle x\rangle}\right\rangle_{T}(\%)$ & \pm 14.0 & \pm 19.2 & \pm 27.6 & \pm 45.1 \\
$\left\langle\frac{u(\langle x\rangle)}{\langle x\rangle}\right\rangle_{T}(\%)$ & \pm 2.1 & \pm 2.8 & \pm 4.4 & \pm 6.9 \\
$\left\langle\frac{U(\langle x\rangle)}{\langle x\rangle}\right\rangle_{T}(\%)$ & \pm 5.0 & \pm 6.4 & \pm 11.3 & \pm 16.7 \\
\hline \hline
\end{tabular}

\section{Expanded uncertainties on the mean and $\mathrm{Co}_{0.97} \mathrm{Ni}_{0.03} \mathrm{Sb}_{3}$ as a standard}

The temperature-averaged (300-700 K) relative expanded uncertainties on the mean of the Seebeck coefficient, electrical resistivity, thermal conductivity, and dimensionless figure of merit $Z T$ at the confidence level of $95 \%$ are reported in Table II. They reach 5\%, 6\%, 11\%, and 17\%, respectively. As a partial and tentative comparison, an expanded uncertainty on the mean value of the Seebeck coefficient in the NIST standard material SRM $3451 \mathrm{Bi}_{2} \mathrm{Te}_{3}$ at $300 \mathrm{~K}$ can be calculated from the data reported in Ref. 8: $r=9, t=2.31$, and $\frac{\sigma(\alpha)}{\langle\alpha\rangle}= \pm 4 \%$ lead to $\frac{U(\alpha)}{\langle\alpha\rangle}= \pm 3 \%$ which is smaller than our $5 \%$ but is not averaged over a broad temperature range. Before establishing $\mathrm{Co}_{0.97} \mathrm{Ni}_{0.03} \mathrm{Sb}_{3}$ skutterudite as an n-type thermoelectric standard reference material for the figure of merit, long-term stability upon cycling should be carefully examined. However, the above moderate values of expanded uncertainty on the mean reflect the homogeneity of the thermoelectric properties of the present sample and are a very encouraging and important step towards considering $\mathrm{Co}_{0.97} \mathrm{Ni}_{0.03} \mathrm{Sb}_{3}$ skutterudite as a SRM for ZT.

\section{SUMMARY}

The uncertainties on the high temperature Seebeck coefficient, electrical resistivity, thermal conductivity, and dimensionless thermoelectric figure of merit have been derived from a statistical treatment of data measured by several European laboratories on the $\mathrm{Co}_{0.97} \mathrm{Ni}_{0.03} \mathrm{Sb}_{3}$ skutterudite. Grossly speaking, these uncertainties increase with temperature, reflecting growing methodological difficulties to measure these quantities when temperature increases. The temperatureaveraged relative uncertainties $(300-700 \mathrm{~K}$ is the temperature window) amount to $6 \%, 8 \%, 11 \%$, and $19 \%$ for the Seebeck coefficient, resistivity, thermal conductivity, and $Z T$, respectively. Likewise prior round robin tests, our results confirm that the thermal conductivity is the critical parameter in determining the accurate $Z T$ value of a material. Because the thermoelectric properties of the present sample were found to be homogeneous, skutterudites may become, in the near future, good thermoelectric standard materials.

\section{ACKNOWLEDGMENTS}

This work was partially funded by the CNRS "Groupement de Recherche Thermoélectricité” (GDR N³382).

\footnotetext{
${ }^{1}$ T. C. Harman, J. H. Cahn, and M. J. Logan, J. Appl. Phys. 30(9), 1351 (1959).

${ }^{2}$ T. M. Tritt, "Electrical and thermal transport measurement techniques for evaluation of the figure-of-merit of bulk thermoelectric materials," in Thermoelectrics Handbook: Macro to Nano, edited by D. M. Rowe (CRC Taylor \& Francis, Boca Raton, 2006)

${ }^{3}$ Working Group 1 of the Joint Committee for Guides in Metrology, Evaluation of Measurement Data-Guide to the Expression of Uncertainty in Measurement (GUM) (Bureau International des Poids et Mesures, 2008), http://www.bipm.org/utils/common/documents/jcgm/JCGM_100_2008_F. pdf.
} 
${ }^{4}$ F. X. Bally and J. M. Berroir, Bull. Union Professeurs Phys. Chim. 928, 995 (2008), available online at http://www.udppc.asso.fr/bupdoc/consultation/ une_fiche.php?ID_fiche $=20802$.

${ }^{5} \mathrm{~S}$. Bell, A Beginner's Guide to Uncertainty of Measurement (NPL, Teddington, 1999), http://www.wmo.int/pages/prog/gcos/documents/gruanmanuals/ UK_NPL/mgpg11.pdf.

${ }^{6} \mathrm{~J}$. Taylor, An Introduction to Error Analysis, 2nd ed. (University Science Books, Sausalito, USA, 1997).

${ }^{7}$ L. Bertini, K. Billquist, M. Christensen, C. Gatti, L. Holmgren, B. Iversen, E. Mueller, M. Muhammed, G. Noriega, A. Palmqvist, D. Platzek, D. M. Rowe, A. Saramat, C. Stiewe, M. Toprak, S. G. K. Williams, and Y. Zhang, "Standardisation in thermoelectric transport properties measurementsThe Cardiff NEDO laboratories and DLR cologne program," in TwentySecond International Conference on Thermoelectrics, Proceedings Ict '03 (IEEE, Piscataway, 2003), pp. 532-536.

${ }^{8}$ N. D. Lowhorn, W. Wong-Ng, W. Zhang, Z. Q. Lu, M. Otani, E. Thomas, M. Green, T. N. Tran, N. Dilley, S. Ghamaty, N. Elsner, T. Hogan, A. D. Downey, Q. Jie, Q. Li, H. Obara, J. Sharp, C. Caylor, R. Venkatasubramanian, R. Willigan, J. Yang, J. Martin, G. Nolas, B. Edwards, and T. Tritt, Appl. Phys. A: Mater. Sci. Process. 94(2), 231-234 (2009).

${ }^{9}$ Z. Q. J. Lu, N. D. Lowhorn, W. Wong-Ng, W. Zhang, E. L. Thomas, M Otani, M. L. Green, T. N. Tran, C. Caylor, N. R. Dilley, A. Downey, B. Edwards, N. Elsner, S. Ghamaty, T. Hogan, Q. Jie, Q. Li, J. Martin, G. Nolas, H. Obara, J. Sharp, R. Venkatasubramanian, R. Willigan, J. Yang, and T. Tritt, J. Res. Natl. Inst. Stand. Technol. 114(1), 37-55 (2009).

${ }^{10}$ H. Wang, W. D. Porter, H. Boettner, J. Koenig, L. Chen, S. Bai, T. M. Tritt, A. Mayolet, J. Senawiratne, C. Smith, F. Harris, P. Gilbert, J. W. Sharp, J. Lo, H. Kleinke, and L. Kiss, J. Electron. Mater. 42(4), 654-664 (2013).
${ }^{11}$ H. Wang, W. D. Porter, H. Boettner, J. Koenig, L. Chen, S. Bai, T. M. Tritt, A. Mayolet, J. Senawiratne, C. Smith, F. Harris, P. Gilbert, J. Sharp, J. Lo, H. Kleinke, and L. Kiss, J. Electron. Mater. 42(6), 1073-1084 (2013).

${ }^{12}$ P. Dordor, E. Marquestaut, C. Salducci, and P. Hagenmuller, Rev. Phys. Appl. 20, 795 (1985).

${ }^{13}$ P. Dordor, E. Marquestaut, and G. Villeneuve, Rev. Phys. Appl. 15, $1607-$ 1612 (1980).

${ }^{14}$ K. Knizek, J. Hejtmanek, Z. Jirak, C. Martin, M. Hervieu, B. Raveau, G. André, and F. Bourée, Chem. Mater. 16, 1104 (2004).

${ }^{15}$ Z. Jirak, J. Hejtmanek, K. Knizek, and M. Veverka, Phys. Rev. B 78, 014432 (2008).

${ }^{16}$ C. Byl, D. Bérardan, and N. Dragoe, Meas. Sci. Technol. 23, 035603 (2012).

${ }^{17}$ O. Rouleau and E. Alleno, Rev. Sci. Instrum. 84(10), 105103 (2013).

${ }^{18}$ A. T. Burkov, "Mesurements of resistivity and thermopower: Principles and practical realization," in Thermoelectrics Handbook: Macro to Nano, edited by D. M. Rowe (CRC, Boca Raton, 2006).

${ }^{19}$ J. Martin, T. Tritt, and C. Uher, J. Appl. Phys. 108(12), 121101 (2010).

${ }^{20}$ H. Anno, K. Matsubara, Y. Notohara, T. Sakakibara, and H. Tashiro, J. Appl. Phys. 86, 3780 (1999)

${ }^{21}$ J. S. Dyck, W. Chen, J. Yang, G. P. Meisner, and C. Uher, Phys. Rev. B 65, 115204 (2002).

${ }^{22}$ S. Katsuyama, M. Watanabe, M. Kuroki, T. Maehala, and M. Ito, J. Appl. Phys. 93(5), 2758 (2003).

${ }^{23}$ E. Alleno, E. Zehani, and O. Rouleau, J. Alloys Compd. 572, 43 (2013).

${ }^{24}$ W. J. Parker, R. J. Jenkins, C. P. Butler, and G. L. Abbott, J. Appl. Phys. 32(9), 1679-1684 (1961).

${ }^{25}$ R. D. Cowan, J. Appl. Phys. 34(4), 926-927 (1963).

${ }^{26}$ J. A. Cape and G. W. Lehmann, J. Appl. Phys. 34, 1909 (1963). 